\title{
A Study on Pulmonary Tuberculosis and Risk Factors in New and Re-Treated Presumptive Patients at Wad Madani Tuberculosis Center, Sudan (2018-2019): A Cross-Sectional Study
}

\author{
Zeinab H. Alfaham1, Elhadi A. Ahmed1, Elamin M. Ibrahim², Mohamed Soud Mohamed', \\ Ameer A. Mohamed4, Ayman Mahjob5, Mubarak A. Elshafia6, Bakri Y. M. Nour ${ }^{7 *}$ \\ ${ }^{1}$ Department of Medical Microbiology, Faculty of Medical Laboratory Sciences, University of Gezira, Wad Medani, Sudan \\ ${ }^{2}$ Department of Microbiology, Faculty of Medical Laboratory Sciences, University of Khartoum, Khartoum, Sudan \\ ${ }^{3}$ Department of Surgery, Faculty of Medicine, University of Gezira, Wad Medani, Sudan \\ ${ }^{4}$ Department of Medicine, Wad Medani Teaching Hospital, Gezira State Ministry of Health, Wad Medani, Sudan \\ ${ }^{5}$ Wad Madani Tuberculosis Center, Gezira State Ministry of Health, Wad Medani, Sudan \\ ${ }^{6}$ Department of Haematology and Immunohaematology, Faculty of Medical Laboratory Sciences, University of Gezira, \\ Wad Medani, Sudan \\ ${ }^{7}$ Department of Medical Parasitology, Faculty of Medical Laboratory Sciences, University of Gezira, Wad Medani, Sudan \\ Email: ^bakrinour@gmail.com
}

How to cite this paper: Alfaham, Z.H., Ahmed, E.A., Ibrahim, E.M., Mohamed, M.S., Mohamed, A.A., Mahjob, A., Elshafia, M.A. and Nour, B.Y.M. (2022) A Study on Pulmonary Tuberculosis and Risk Factors in New and Re-Treated Presumptive Patients at Wad Madani Tuberculosis Center, Sudan (2018-2019): A Cross-Sectional Study. Journal of Tuberculosis Research, 10, 18-27. https://doi.org/10.4236/jtr.2022.101002

Received: January 4, 2022

Accepted: March 5, 2022

Published: March 8, 2022

Copyright ( 2022 by author(s) and Scientific Research Publishing Inc. This work is licensed under the Creative Commons Attribution International License (CC BY 4.0).

http://creativecommons.org/licenses/by/4.0/ (c) (i) Open Access

\begin{abstract}
Introduction: The increase in cases of drug-resistant pulmonary tuberculosis, especially in endemic areas, is mainly associated with re-treatment, although resistant tubercle bacilli can be easily transmitted between all susceptible persons. Objective: The study aimed to describe pulmonary tuberculosis, risk factors and MDR in new and re-treated suspected patients attending Wad Madani Tuberculosis Center that provides service in central Sudan. Methods: Cross-sectional laboratory based study among 300 presumptive pulmonary tuberculosis patients during 2018 and 2019 was conducted. Cases were divided into new and re-treated. Mycobacterium tuberculosis DNA and rpoB gene of multi-drug resistance (MDR) were detected in sputum samples by GeneXpert assay as manufacturer instructions. Results: Out of 300 suspected participants, 34\% (103/300) were diagnosed as pulmonary tuberculosis using GeneXpert method. The frequency of males, the age group from 21 to 40 and rural housing were the most with percentage reach $68 \%$ (70/103), 51\% (53/103) and 58.3\% (60/103) respectively. All observed symptoms were significantly associated with pulmonary tuberculosis. New cases represented $59.2 \%$ (61/103) while re-treated was $40.8 \%$ (39/103). The overall frequency of MDR patients was 9.7\% (10/103) of which 50\% (5/103) had relapse situation. Conclusion: It appeared that the cases of MDR pulmonary
\end{abstract}


tuberculosis are on the increase compared to previous findings, recommended measures must be taken to control the spread of tuberculosis and the causes of re-treatment and relapse must be studied.

\section{Keywords}

MDR, Pulmonary Tuberculosis, Relapse, Sudan

\section{Introduction}

During the time period from 2006 to 2015, Sudan recorded an increasing in cases of tuberculosis in both new and resistant cases, which indicates the absence or ineffectiveness of control measures for limiting the spread [1]. In many developing countries tuberculosis remains a major cause of morbidity and mortality and moreover, cases and deaths due to tuberculosis in developing countries are estimated at about $95 \%$ and $98 \%$ respectively [2]. Of the total cases of tuberculosis infection in the Eastern Mediterranean Region, Sudan includes 11\% to 15\%, with incidence to infection, which reaches the highest level in 2010 (119 per 100.000 population), then incidence rate was recorded to be 77 per 100.000 population in 2018 [1] [3].

Risk factors of acquiring TB could be categorized into factors that related to susceptible person and contact situation, this includes: age, sex, HIV confection, diabetes, immunosuppressive drugs medications, renal failure, alcohol intake. While risk factors related to drug resistance occurring include failure, relapse, and loss of follow-up [4]. Since the HIV is the most important pathogen that weakens the immune system, its spread in community increases the incidence of infectious diseases such as tuberculosis. In Eastern Sudan, which represents the border between Sudan and Ethiopia, TB/HIV co-infection constituted $18.3 \%$ as documented by Tajeldin et al. [5]. Records showed a significant difference in the susceptible to tuberculosis among health-care workers in the low- and middle-income and high-income countries; in most developing countries medical personnel work at non-preventable conditions beside environmental pollution in hospitals, shortage of disinfection and other infection control measures [6]. According to WHO Sudan classified as country with medium prevalence for diabetes [7] which is another risk factor for acquiring tuberculosis, in adult a percentage $7.7 \%$ had been reported as prevalence rate in Sudan [8].

In Sudan before 2017 MDR cases were ignored due to the inactivation of gene Xpert diagnosis system and thus resistance data are limited record, after 2017 drug resistance cases appear with frequency not recorded and in 2018 reported as $3.8 \%$ for new cases and $18 \%$ for re-treated cases of tuberculosis. Continuous monitoring of tuberculosis prevents spread of TB cases and helps control program [1]. In 2017 in Sudan, it was estimated about 600 patients among pulmonary TB patients; $3.5 \%$ of new TB cases and $18 \%$ of pre-treated cases are MDR/ RR-TB cases [9]. From study data many reasons of drug resistance were ob- 
served; these were due to description of incorrect practices and poor enrollment to anti-TB medications infection [10] [11] [12]. Drug resistance can occur also due to the consequences of primary infection. There for, for treated this cases need intensive interventions. MDR-TB is characterized by the cost of expensive treatment, long period of indication, decrease efficacy compared to susceptible medications, and enormous side-effects of treatment [13].

Indeed, few scattered data were directed to know the outcome of treatment of MDR-TB specially in Sudan where resources is limited. [14] [15] [16] furthermore, this situation makes Sudan at level lower than the goal required to be achieved by WHO [17].

According to WHO classification, tuberculosis patients' status could be identified as new and re-treated cases; re-treated patients include relapse and failure treatment. Relapsing involves those who infected again after completing the period of 6-month treatment, and failure treatment characterized by positive $\mathrm{ZN}$ smear after first two months of starting anti-tuberculosis treatment [1]. This study identified MDR among new and re-treated pulmonary tuberculosis cases attending Wad Madani Tuberculosis Center using GeneXpert assay.

\section{Methods}

\subsection{Settings of the Study}

The study followed cross-sectional design during 2018 and 2019. Conducted area was Wad Madani Tuberculosis Center where the majority of admitted patients were from Gezira State. According to 2017 Gezira State population was estimated to be 5,096,920.

\subsection{Case Definition and Sample Size}

This study enrolled patients whom suspected to have pulmonary tuberculosis and referred to the Wad Madani Tuberculosis Center during the study periode. Admitted patients had tuberculosis suspected chest X-ray report and they complain of chronic pulmonary signs and symptoms according to inclusion criteria. Cases were categorized into new and re-treated. The later more classified into relapse, failure of treatment and loss of follow-up. Three hundred cases were recruited.

\subsection{Sputum Collection and De-Contamination}

Early morning sputum was targeted and collected in a suitable plastic container. Patients were constricted to collect more $2 \mathrm{ml}$ of sample after deep coughing. Saliva and food remnants contaminated sputum was rejected. Macroscopical examination is done for the presence of blood. Safety considerations followed were; sodium hydroxide decontamination and personal protective equipments [18].

\subsection{GeneXpert Assay Test and Interpretation of Results}

Immediately after sputum collection, MTB DNA and rpoB gene were examined 
in the Medical Laboratory of Wad Madani Tuberculosis Center using (Cepheid, GeneXpert IV) Specimens were prepared to be proceed by GeneXpert machine according to the manufacture instruction [19]. Results were interpreted for the presence of MTB DNA by 5 fluorescent labeled probes; A, B, C, D and E. Detection of 2 or more probes considered positive while no or one probe detection indicated negative result. Degrees of positivity for each sample were determined as high, medium, low and very low. MDR MTB was recorded by the presence of rpoB gene which indicated rifampicin resistant strain; one probes or more negative indicated MDR and all probes positive resulted in no MDR.

\section{Results}

From total of 300 studied patients with pulmonary tuberculosis symptoms, 34\% (103/300) were diagnosed as sputum positive by GeneXpert assay. High, medium, low and very low DNA positivity were reported with $16.5 \%$ (17/103), $51.5 \%(53 / 103), 23.3 \%(24 / 103)$ and $8.7 \%$ (9/103) frequency respectively. Males were predominated and represented 68\% (70/103). Age group from 21 to 40 was the most frequent $51.5 \%(53 / 103)$ and rural residence occurred with $58.3 \%$ (60/103). Symptoms; fever, night sweat, bloody cough, weight loss and appetite loss were significantly associated with pulmonary tuberculosis. Prolong cough was recorded in all cases. No association was found between pulmonary tuberculosis and studied risk factors; contact history (Chi-Square 0.309) and HIV (Chi-Square 0.282) (Table 1). While diabetes and renal failure were not documented. New cases of pulmonary tuberculosis among studied subject equal 59.2\% (61/103), relapse status was $22.3 \%$ (23/103) and failure treatment $16.5 \%$ (17/103). MDR tuberculosis was revealed in $9.7 \%$ (10/103) of all cases of which relapse involved 50\% (5/10) (Table 2).

\section{Discussion}

The dilemma of tuberculosis drug resistance cases is increased with the spread of disease transmission and, accordingly, the resistant causative agent. Regrettably, these drug-resistant cases are associated with an increase in the number of deaths [20]. In the near time during 2018, rifampicin as the most functional first line anti-tubercular expressed resistance of 500.000 cases world-wide [9]. Many factors make drug-resistant tuberculosis an exceptional problem to deal with. In terms of medication, the alternative use of second treatment line includes additional antibiotics with more side effects, high cost and a longer duration [21] [13]. Molecular tests for drug-resistant tuberculosis are characterized by rapid and accurate diagnosis, which made them the most widely used [22]. As documented by WHO in 2015, Sudan occurred in the 30 high TB burden countries. The data related to the drug-resistance is of great importance, especially since Sudan is not among the countries in which resistant tuberculosis is spread [23].

This study found $9.7 \%$ of pulmonary TB cases as multi-drug resistance and this percentage is slightly more than the last recorded in Sudan in 2018, which 
amounted to 7.7\% [1]. Near finding was obtained by Aricha and his group in Kenya in 2019 [24] and Ethiopia [25]. However low and or/very low frequency occurred in North Africa and developed countries. It is noted that the increase in MDR-TB is directly proportional to the cases recorded in the country, therefore, the spread must be controlled first in order to reduce the number of drug resistant cases.

Table 1. Baseline data of pulmonary tuberculosis subject. No 103

\begin{tabular}{|c|c|c|c|c|}
\hline & & Frequency & Percent & Chi-Square \\
\hline \multirow{2}{*}{ Gender } & Mae & 70 & 68.0 & \multirow{2}{*}{0.611} \\
\hline & Female & 33 & 32.0 & \\
\hline \multirow{4}{*}{$\begin{array}{c}\text { Age } \\
\text { category/year }\end{array}$} & Less than 20 & 14 & 13.6 & \multirow{4}{*}{0.179} \\
\hline & $21-40$ & 53 & 51.5 & \\
\hline & $41-60$ & 23 & 22.3 & \\
\hline & More than 60 & 13 & 12.6 & \\
\hline \multirow{6}{*}{ Occupation } & House wife & 15 & 14.6 & \multirow{6}{*}{0.082} \\
\hline & Worker & 39 & 37.9 & \\
\hline & Student & 8 & 7.8 & \\
\hline & Farmer & 24 & 23.3 & \\
\hline & Employer & 9 & 8.7 & \\
\hline & Unemployed & 8 & 7.8 & \\
\hline \multirow{2}{*}{ Residence } & Rural & 60 & 58.3 & \multirow{2}{*}{0.888} \\
\hline & Urban & 43 & 41.7 & \\
\hline \multirow{2}{*}{ Fever } & Yes & 38 & 36.9 & \multirow{2}{*}{0.000} \\
\hline & No & 65 & 63.1 & \\
\hline \multirow{2}{*}{ Night sweat } & Yes & 28 & 27.2 & \multirow{2}{*}{0.000} \\
\hline & No & 75 & 72.8 & \\
\hline \multirow{2}{*}{ Bloody cough } & Yes & 58 & 56.3 & \multirow{2}{*}{0.000} \\
\hline & No & 45 & 43.7 & \\
\hline \multirow{2}{*}{ Weight loss } & Yes & 73 & 70.9 & \multirow{2}{*}{0.004} \\
\hline & No & 30 & 29.1 & \\
\hline \multirow{2}{*}{ Appetite loss } & Yes & 93 & 90.3 & \multirow{2}{*}{0.000} \\
\hline & No & 10 & 9.7 & \\
\hline \multirow{2}{*}{ Contact history } & Yes & 5 & 4.9 & \multirow{2}{*}{0.309} \\
\hline & No & 98 & 95.1 & \\
\hline \multirow{2}{*}{ HIV } & Yes & 4 & 3.9 & \multirow{2}{*}{0.282} \\
\hline & No & 99 & 96.1 & \\
\hline
\end{tabular}


Table 2. Distribution of pulmonary tuberculosis cases according to the admission status and MDR detection. No 103

\begin{tabular}{ccccc}
\hline Patient's status & Frequency & Percent & MDR positive & MDR negative \\
\hline New & 61 & 59.3 & 3 & 58 \\
Relapse & 23 & 22.3 & 5 & 18 \\
Failure treatment & 17 & 16.5 & 2 & 15 \\
Loss of follow-up & 2 & 1.9 & 0 & 2 \\
Total & 103 & 100 & 10 & 93 \\
\hline
\end{tabular}

Because of importance, we could not detect highly resistant cases such as extensive drug resistance tuberculosis XDR-TB due to lack of advance laboratory technology for testing [26] especially in Sudan. There for there is a need to detect the actual occurrence of XDR in tuberculosis endemic regions.

Although the proportion of female in the community is equal or more than male, we observed low rate of TB among studied women. Similarly, high rate of male infection reported in Sudan [27] and India [28]. From our result which revealed $69.8 \%$ of TB positive cases as workers and farmers, male more likely to be expose to MTB during day work [29]. Other behaviors common in male rather than female are smoking and tobacco [30]. In line, some studied elicited hormonal and immunological variation between female and male to be susceptibility determinant to infectious diseases [31] [32]. In contrast to above mentioned the incidence of pulmonary TB in female was greater than male in three related countries; Iran [33], Afghanistan [34] and Pakistan [35], social-cultural and economic factors supposed to be predictors for this situation, hence, studies are needed for more explanation.

The rural population formed a larger proportion of pulmonary tuberculosis in this current study although we showed no significant relationship, there is no doubt that the quality of living and health is lower than that of urban residents. The most affected age group among studied patients was from 21 to 40 years which had been noted in many other findings; in Sudan 27 and Kenya [36]. These results encourage further studies to re-evaluate host status in terms of susceptibility to infection and immunity status, prevalence of the causative agent [37] and vaccination.

With pulmonary tuberculosis, many studies deal with the social, clinical factors and admission status of patients some of these studies did not show a relationship between the tuberculosis and social factors [38] [39], and the results of our studies are in agreement.

In the present study cases of treatment failure was repeated by $16.5 \%$, and this was determined by positive $\mathrm{ZN}$ smear after the first two months of treatment. The possible reasons of failure could be; the inadequate TB treatment centers and their far distance from the rural areas which included most cases [40]; in addition to the prolong medication period and the general weakness of the patients due to the loss of appetite and weight [41] [42]. 
Relapse after completing tuberculosis treatment is of a global concern [43] and our study recorded alarming rate of $22 \%$; confirming that tuberculosis is still an endemic in Sudan. It is worth noting that, relapse is associated with drugresistance tuberculosis, and it is not surprising that $50 \%$ of relapse cases in this study were MDR [44] [45], for comparison the MDR rate of new TB cases in Sudan was estimated in 2019 to be $3.5 \%$ [46].

In fact, this study did not identify the level of rifampicin resistance through rpoB gene sequencing for the detection of existent mutations, which can improve the drug selection and physician decisions [47].

In conclusion, the rates of drug-resistant tuberculosis are increasing even more in cases of relapse, which requires dealing with this problem in its initial stages, for example, increasing treatment centers and early diagnosis in peripheral places, and accuracy in following up on patients.

\section{Conflicts of Interest}

The authors declare no conflicts of interest regarding the publication of this paper.

\section{References}

[1] Sudan, Federal Ministry of Health, PHC, Communicable and Noncommunicable Diseases Directorate (2018) Sudan National TB Management Guidelines.

[2] Getahun, B., Ameni, G., Biadgilign, S. and Medhin, G. (2011) Mortality and Associated Risk Factors in a Cohort of Tuberculosis Patients Treated under DOTS Programme in Addis Ababa, Ethiopia. BMC Infectious Diseases, 11, Article No. 127. https://doi.org/10.1186/1471-2334-11-127

[3] Stop TB Partnership (2004) Compendium of Indicators for Monitoring and Evaluation National Tuberculosis Programs. World Health Organization, Geneva, WHO/ HTM/TB/2004.344. http://apps.who.int/iris/bitstream/10665/68768/1/WHO HTM TB 2004.344.pdf

[4] Romieu and Trenga, C. (2001) From Exposure to Disease: The Role of Environmental Factors in Susceptibility to and Development of Tuberculosis. Epidemiologic Reviews, 23, 288-301. https://doi.org/10.1093/oxfordjournals.epirev.a000807

[5] Abdallaha, T.M., et al. (2012) Provider-Initiated HIV Testing and Counseling among Tuberculosis Patients in Kassala, Eastern Sudan. Journal of Infection and Public Health, 5, 63-66. https://doi.org/10.1016/j.jiph.2011.10.001

[6] Joshi, R., Nienhaus, A. and Diel, R. (2005) Review of Epidemiological Studies on the Occupational Risk of Tuberculosis in Low-Incidence Areas. Respiration, 72, 431-446. https://doi.org/10.1159/000086261

[7] Boutayeb, A., Lamlili, E.N.M., Boutayeb, W., Maamri, A., Ziyyat, A. and Ramdani, N. (2012) The Rise of Diabetes Prevalence in the Arab Region. Open Journal of Epidemiology, 2, 55-60. https://doi.org/10.4236/ojepi.2012.22009

[8] International Diabetes Federation (2013) Diabetes Atlas. 6th Edition, Brussels. http://www.idf.org/diabetesatlas

[9] WHO (2018) Multidrug-Resistant Tuberculosis (MDR-TB). https://www.who.int/tb/areas-of-work/drug-resistant-tb/MDR-RR TB factsheet 20 18 Apr2019.pdf?ua $=1$ 
[10] Seaworth, B.J. and Griffith, D.E. (2017) Therapy of Multidrug-Resistant and Extensively Drug-Resistant Tuberculosis. Microbiology Spectrum, 5, 2. https://doi.org/10.1128/microbiolspec.TNMI7-0042-2017

[11] Dean, A.S., Cox, H. and Zignol, M. (2017) Epidemiology of Drug-Resistant Tuberculosis. Advances in Experimental Medicine and Biology, 1019, 209-220. https://doi.org/10.1007/978-3-319-64371-7 11

[12] Wilson, J.W. and Tsukayama, D.T. (2016) Extensively Drug-Resistant Tuberculosis: Principles of Resistance, Diagnosis, and Management. Mayo Clinic Proceedings, 91, 482-495. https://doi.org/10.1016/j.mayocp.2016.01.014

[13] Ahuja, S.D., Ashkin, D., Avendano, M., et al. (2012) Multidrug Resistant Pulmonary Tuberculosis Treatment Regimens and Patient Outcomes: An Individual Patient Data Meta-Analysis of 9,153 Patients. PLOS Medicine, 9, e1001300.

[14] Meressa, D., Hurtado, R.M., Andrews, J.R., et al. (2015) Achieving High Treatment Success for Multidrug-Resistant TB in Africa: Initiation and Scale-Up of MDRTB Care in Ethiopia-An Observational Cohort Study. Thorax, 70, 1181-1188. https://doi.org/10.1136/thoraxjnl-2015-207374

[15] Getachew, T., Bayray, A. and Weldearegay, B. (2013) Survival and Predictors of Mortality among Patients under Multi-Drug Resistant Tuberculosis Treatment in Ethiopia: St. Peter's Specialized Tuberculosis Hospital, Ethiopia. International Journal of Pharmaceutical Sciences and Research, 4, 776-787.

[16] IAMAT (2017) Sudan for Specific Travellers: Tuberculosis. https://www.iamat.org/country/sudan/risk/tuberculosis

[17] Elmadhoun, W.M., Noor, S.K., Bushara, S.O., et al. (2016) Epidemiology of Tuberculosis and Evaluation of Treatment Outcomes in the National Tuberculosis Control Programme, River Nile State, Sudan, 2011-2013. Eastern Mediterranean Health Journal, 22, 95-102. https://doi.org/10.26719/2016.22.2.95

[18] Elfaham, Z., Ibrahim, E., Ahmed, E., Mohammed, A. and Nour, B. (2021) Pulmonary Tuberculosis among Suspected Sudanese Patients in Wad Madani Tuberculosis Center. Open Journal of Medical Microbiology, 11, 298-307.

https://doi.org/10.4236/ojmm.2021.114019

[19] Hakeem, A., Hussain, M.S. and Sarwar, M.I. (2013) Gene Xpert MTB/RIF-A Novel Diagnostic Tool for Tuberculosis in Pulmonary Samples. IOSR Journal of Dental and Medical Sciences, 8, 1-3. https://doi.org/10.9790/0853-0820103

[20] Chung-Delgado, K., et al. (2015) Mortality among MDR-TB Cases: Comparison with Drug-Susceptible Tuberculosis and Associated Factors. PLoS ONE, 10, e0119332. https://doi.org/10.1371/journal.pone.0119332

[21] Dheda, K., Chang, K.C., Guglielmetti, L., et al. (2017) Clinical Management of Adults and Children with Multidrug-Resistant and Extensively Drug-Resistant Tuberculosis. Clinical Microbiology and Infection, 23, 131-140. https://doi.org/10.1016/j.cmi.2016.10.008

[22] Prasad, R., et al. (2018) Multidrug-Resistant Tuberculosis/Rifampicin-Resistant Tuberculosis: Principles of Management. Lung India: Official Organ of Indian Chest Society, 35, 78-81. https://doi.org/10.4103/lungindia.lungindia 9817

[23] WHO (2021, October 14) Fact Sheets. Tuberculosis. https://www.who.int/en/news-room/fact-sheets/detail/tuberculosis

[24] Aricha, S., Kingwara, L., Mwirigi, N., Chaba, L., et al. (2019). Comparison of GeneXpert and Line Probe Assay for Detection of Mycobacterium tuberculosis and Rifampicin-Mono Resistance at the National Tuberculosis Reference Laboratory, Kenya. BMC Infectious Diseases, 19, Article No. 852. https://doi.org/10.1186/s12879-019-4470-9 
[25] Federal Ministry of Health of Ethiopia (FMOH) (2011) Tuberculosis Prevention and Control Programme: Special Issue for World TB Day.

[26] Cheng, V.C.C., Yew, W.W. and Yuen, K.Y. (2015) Diagnostics in MDR-Tuberculosis. European Journal of Clinical Microbiology \& Infectious Diseases, 24, 711-720. https://doi.org/10.1007/s10096-005-0039-1

[27] Banaga, A.S., Siddiq, N.K., Alsayed, R.T., Babiker, R. and Elmusharaf, K. (2016) Prevalence and Presentation of Tuberculosis among Hemodialysis Patients in Khartoum, Sudan. Saudi Journal of Kidney Diseases and Transplantation, 27, 992-996. https://doi.org/10.4103/1319-2442.190873

[28] Borgdor, M.W., Nagelkerke, N.J.D., Dye, C. and Nunn, P. (2000) Gender and Tuberculosis: A Comparison of Prevalence Surveys with Notification Data to Explore Sex Differences in Case Detection. The International Journal of Tuberculosis and Lung Disease, 4, 123-132.

[29] Watkins, R.E. and Plant, A.J. (2006) Does Smoking Explain Sex Differences in the Global Tuberculosis Epidemic? Epidemiology \& Infection, 134, 333-339. https://doi.org/10.1017/S0950268805005042

[30] Lim, S.S., Vos, T., Flaxman, A.D., Danaei, G., Shibuya, K., Adair-Rohani, H., Amann, M. anderson, H.R. andrews, K.G., Aryee, M., et al. (2012) A Comparative Risk Assessment of Burden of Disease and Injury Attributable to 67 Risk Factors and Risk Factor Clusters in 21 Regions, 1990-2010: A Systematic Analysis for the Global Burden of Disease Study 2010. The Lancet, 380, 2224-2260.

[31] Giefing-Kroll, C., Berger, P., Lepperdinger, G. and Grubeck-Loebenstein, B. (2015) How Sex and Age Affect Immune Responses, Susceptibility to Infections, and Response to Vaccination. Aging Cell, 14, 309-321. https://doi.org/10.1111/acel.12326

[32] Guess, T.E., Rosen, J.A. and McClelland, E.E. (2018) An Overview of Sex Bias in C. Neoformans Infections. Journal of Fungi (Basel), 4, pii: E49. https://doi.org/10.3390/jof4020049

[33] Kherad, O., Hermann, F.R., Zellweger, J.P., Rochat, T., Jansen, J.P., et al. (2009) Clinical Presentation, Demographics and Outcome of Tuberculosis (TB) in a Low Incidence Area: A 4-Year Study in Geneva, Switzerland. BMC Infectious Diseases, 9, 217-229. https://doi.org/10.1186/1471-2334-9-217

[34] Sabawoon, L.W. and Sato, H. (2012) Sex Difference in Tuberculosis in Afghanistan: A National Cohort Study. Mycobacterial Diseases, 2012, 1-5. https://doi.org/10.4172/2161-1068.1000115

[35] Codlin, A.J., Khowaja, S., Chen, Z., Rahbar, M.H., Qadeer, E., et al. (2011) Short Report: Gender Differences in Tuberculosis Notification in Pakistan. American Journal of Tropical Medicine and Hygiene, 85, 514-517.

https://doi.org/10.4269/ajtmh.2011.10-0701

[36] Muia, P.K., Ngugi, M.P. and Mburu, D.N. (2017) Performance of GeneXpert Assay in Detecting Pulmonary Tuberculosis and Rifampicin Resistance in Patients Attending Kitui County Hospital, Kenya. Journal of Tropical Diseases, 5, Article ID: 1000246. https://doi.org/10.4172/2329-891X.1000246

[37] Narasimhan, P., Wood, J., Macintyre, C.R. and Mathai, D. (2013) Risk Factors for Tuberculosis. Pulmonary Medicine, 2013, Article ID: 828939.

https://doi.org/10.1155/2013/828939

[38] Morsy, A.M., Zaher, H.H., Hassan, M.H. and Shouman, A. (2003) Predictors of Treatment Failure among Tuberculosis. Patients under DOTS Strategy in Egypt. Eastern Mediterranean Health Journal, 9, 689-701.

https://doi.org/10.26719/2003.9.4.618 
[39] De Albuquerque, M.F., Ximenes, R.A., Lucena, S., et al. (2007) Factors Associated with Treatment Failure, Drop Out, and Death in a Cohort of Tuberculosis Patients in Recife, Pernambuco State, Brazil. Cadernos de Saúde Pública, 23, 1573-1582.

[40] Shargie, E. and Lindtjorn, B. (2007) Determinants of Treatment Adherence among Smear-Positive Pulmonary Tuberculosis Patients in Southern Ethiopia. PLOS Medicine, 4, e37. https://doi.org/10.1371/journal.pmed.0040037

[41] Rossana, A., et al. (1996) Clinical Predictors of Response to Tuberculosis Chemotherapy. Philippine Journal of Microbiology and Infectious Diseases, 25, 1820.

[42] Keane, V.P., de Klerk, N., Krieng, T., Hammond, G. and Musk, W.A. (1997) Risk Factors for the Development of Non-Response to First Line Treatment for Tuberculosis in Southern Vietnam. International Journal of Epidemiology, 26, 1115-1120. https://doi.org/10.1093/ije/26.5.1115

[43] Guerra-Assunção, J.A., Houben, R.M., Crampin, A.C., Mzembe, T., Mallard, K., Coll, F., et al. (2015) Recurrence Due to Relapse or Reinfection with Mycobacterium tuberculosis. A Whole-Genome Sequencing Approach in a Large, Population-Based Cohort with a High HIV Infection Prevalence and Active Follow-Up. The Journal of Infectious Diseases, 211, 1154-1163. https://doi.org/10.1093/infdis/jiu574

[44] Cox, H., Kebede, Y., Allamuratova, S., Ismailov, G., Davletmuratova, Z., Byrnes, G., et al. (2006) Tuberculosis Recurrence and Mortality after Successful Treatment: Impact of Drug Resistance. PLOS Medicine, 3, e384. https://doi.org/10.1371/journal.pmed.0030384

[45] Shen, X., Yang, C., Wu, J., Lin, S., Gao, X., Wu, Z., et al. (2017) Recurrent Tuberculosis in an Urban Area in China: Relapse or Exogenous Reinfection? Tuberculosis, 103, 97-104. https://doi.org/10.1016/j.tube.2017.01.007

[46] Ali, M.H., Alrasheedy, A.A., Kibuule, D., Godman, B., Hassali, M.A. and Ali, H.M.H. (2019) Assessment of Multidrug-Resistant Tuberculosis (MDR-TB) Treatment Outcomes in Sudan, Findings and Implications. Expert Review of Anti-Infective Therapy, 17, 927-937. https://doi.org/10.1080/14787210.2019.1689818

[47] Hirani, N., Joshi, A., Anand, S., Chowdhary, A., Ganesan, K., Agarwal, M. and Phadke, N. (2020) Detection of a Novel Mutation in the rpoB Gene in a Multidrug Resistant Mycobacterium tuberculosis Isolate Using Whole Genome Next Generation Sequencing. Journal of Global Antimicrobial Resistance, 22, 270-274.

https://doi.org/10.1016/j.jgar.2020.03.004 